\begin{tabular}{|c|c|}
\hline 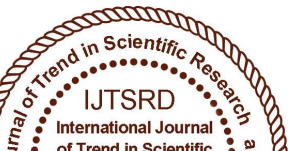 & $\begin{array}{l}\text { International Journal of Trend in Scientific } \\
\text { Research and Development (IJTSRD) }\end{array}$ \\
\hline 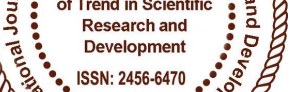 & International Open Access Journal \\
\hline 000 & ISSN No: 2456 - 6470 | www.ijtsrd.com | Volume - 2 | Issue - 3 \\
\hline
\end{tabular}

\title{
Design and Implementation of Human Stress Detector
}

\author{
${ }^{1}$ Prajakta J. Jadhav, ${ }^{1}$ Shital S. Jadhav, ${ }^{1}$ Pravinkumar V. Gund, ${ }^{2}$ Mrs.Madhura G. Kulkarni \\ ${ }^{1}$ UG Student, ${ }^{2}$ Assistant Professor, \\ Department of Electronics \& Telecommunication Engineering, \\ Brahmdevdada Mane Institute of Technology, Solapur, Maharashtra, India
}

\begin{abstract}
Today's life is full of frustration, deadlines and demands. For many people, stress is common that it has become an integral part of life. Stress is body's way of responding to any kind of demand and threat. When you feel threatened, your nervous system responds by re-leasing flood of stress hormones including adrenaline due to which body conductance changes, heart beat changes, blood pressure raises and breath quickness increases. They directly correlate the level of stress to one's emotion or mood [1]. In the proposed system heart beat rate, body temperature and moisture are the three informative signals that are used to determine the level of stress.
\end{abstract}

Keywords: Pulse sensor, Stress detector, Arduino, Temperature sensor

\section{INTRODUCTION:}

As we move into the new era, the people of today's generation are so busy that they want even think about their health so this stress detector we detect stress and eliminates the gap between professional and personal life[1].

According to American Psychological Association, stress levels for Americans are continuing to drop but they still remain high and exceed what Americans consider to be healthy. The 2011 stress in America survey stated that $22 \%$ of Americans reported extreme stress and the impact of this stress is negatively affecting physical health Also, when stress occurs, and the person is experiencing symptoms[2]. So detection of stress is very important according to that doctor gives very accurate treatment to patient.
For example your body can still react as if you are facing a life-or-death situation. when you repeatedly experience the flight or fight stress response in your daily real life, it can raised blood pressure, suppress the immune system, increase the risk of heart attack and stroke speed up aging process and leave you vulnerable to a host of mental and emotional problems such as[1]

- Heart disease

- Depression

- Increase in body temperature

- Digestive problems

To overcome this problem, we have designed stress detector so that it will be helpful to doctors giving best treatment knowing the stress level of patient such as medicine or musical therapy to decrease his stress.

\section{HARDWARE USED}

The hardware tools used include Arduino UNO, Pulse sensor, Temperature sensor (LM35), moisture sensor. The software tool used in the project is Arduino IDE which is an open source tool.

\section{Arduino uno}

Arduino uno is development board based on the ATmega328p microcontroller. It has 14 digital input/ output pins (of which 6 can be used as PWM outputs ), 6 analog inputs, a $16 \mathrm{MHz}$ quartz crystal, a USB connection, a power jack and this board is programmed using arduino software (IDE). It operates at $5 \mathrm{v}$ with a flash memory of around $32 \mathrm{~KB}$ [1] 


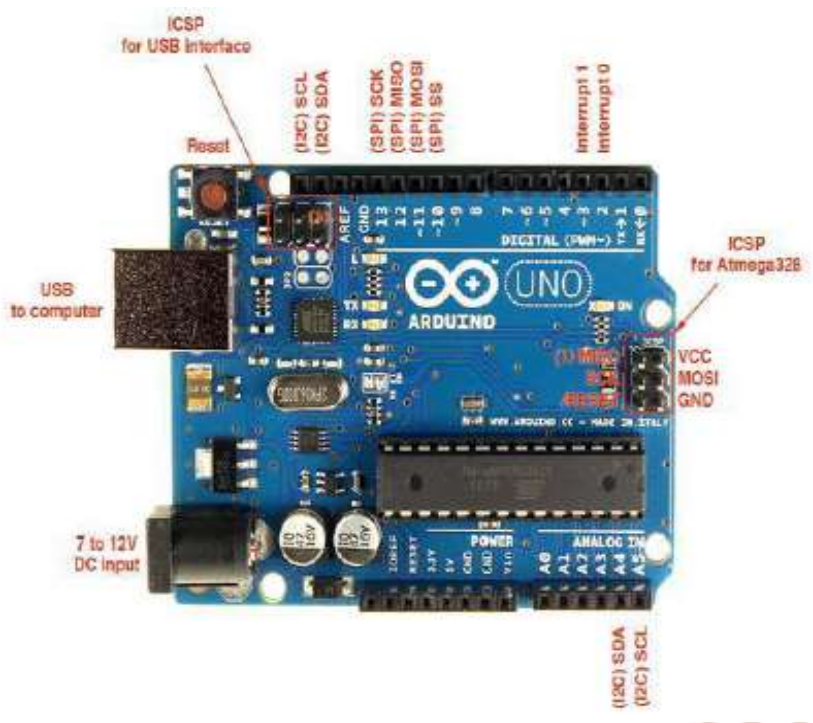

Fig (1)-Arduino uno board

or trimming to provide typical accuracies of $\mathrm{c}$ at room temperature and cover a full $55 \mathrm{C}$ to $150 \mathrm{C}$ temperature range.

Lower cost is assured by trimming and calibration at the wafer level[1].

\section{Pulse Sensor}

Heart rate can be measured using the sensor which works on the principle of Photophlethymography. pulse sensor is a well designed plug-and-play heart rate sensor for arduino. The sensor clips onto a fingertip or earlobe and plugs right into arduino with some jumper cables.

It also includes an open source monitoring the levels of your pulse in real time. It can be used by students, artists, athletes, makers and game mobiles develssopers who want to easily incorporate live heart rate data into their project [1].

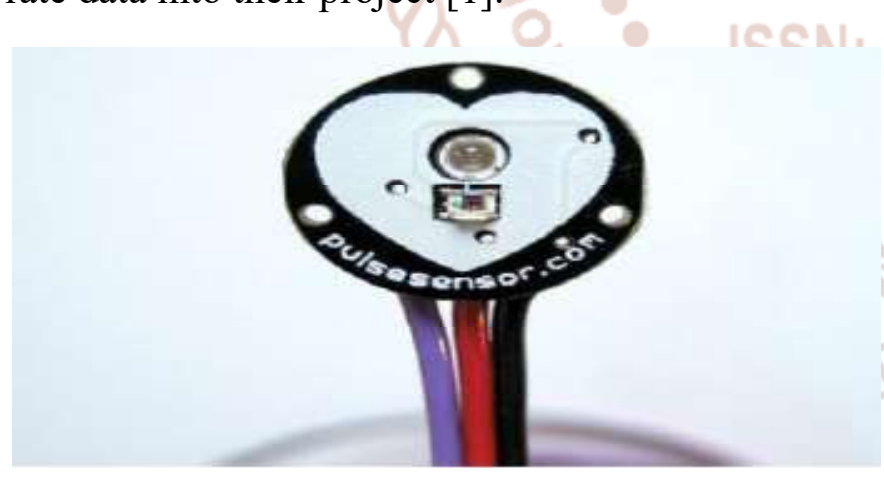

Fig (2) Heartbeat KG011 pulse sensor

\section{Temperature sensor}

The LM35 series are precision integrated circuit temperature device with an output voltage linearly proportional to the centigrade temperature. The LM35 device has an advantage over linear temperature sensors calibrated in Kelvin, as the user is not required to subtract a large constant voltage from the output to obtain convenient centigrade scaling. The LM35 device does not require any external calibration

\section{Moisture sensor}

This sensor can be used to test the moisture of human body, when stress is increased then sweating of human also increased. When sweating is high then level of stress will be high else stress is low level. Module triple output mode, digital output is simple, analog output more accurate, serial output with exact reading [3].

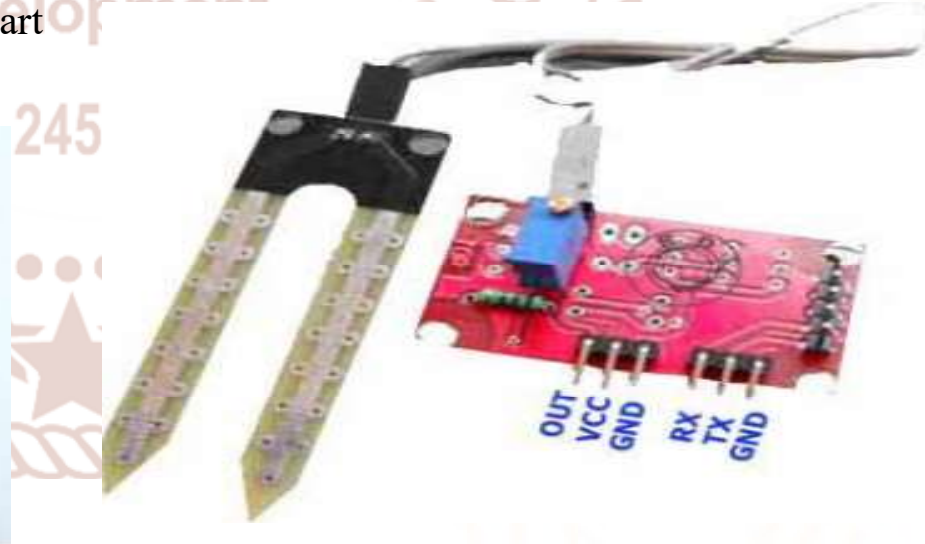

Fig (4) - Moisture sensor

\section{Buzzer}

A buzzer is an audio signaling device, which may be electromechanical, mechanical or piezoelectric. typical use of buzzer in alarm devices and timers .buzzer is an integrated structure of electronic transducers , DC power supply, widely used in computers, printers copiers, alarm and other electronic products for sound devices[4]. 


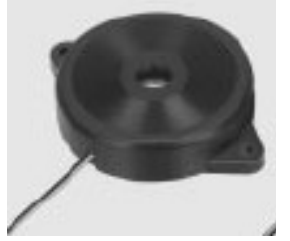

Fig (5) - Piezoelectric buzzer

\section{LCD}

A LCD is an electronic display module which uses liquid crystal to produce visible image. The $16^{*} 2$ translates a display 16 characters per line in 2 such lines. In this LCD each character is displayed in $5 * 7$ pixel matrix. This is powered by $5 \mathrm{v}$ DC, 92 special characters and 8 custom characters. A LCD is used in computers, calculators, television set [5].

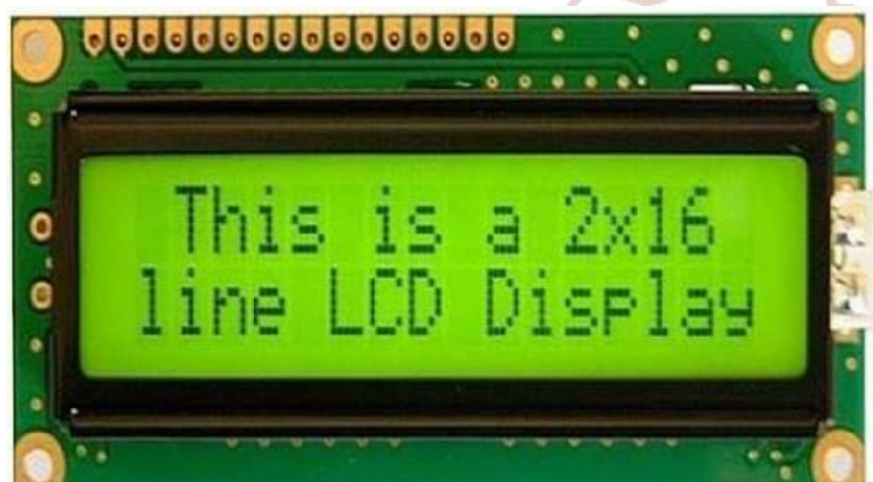

Fig (6) - 16*2 LCD Display

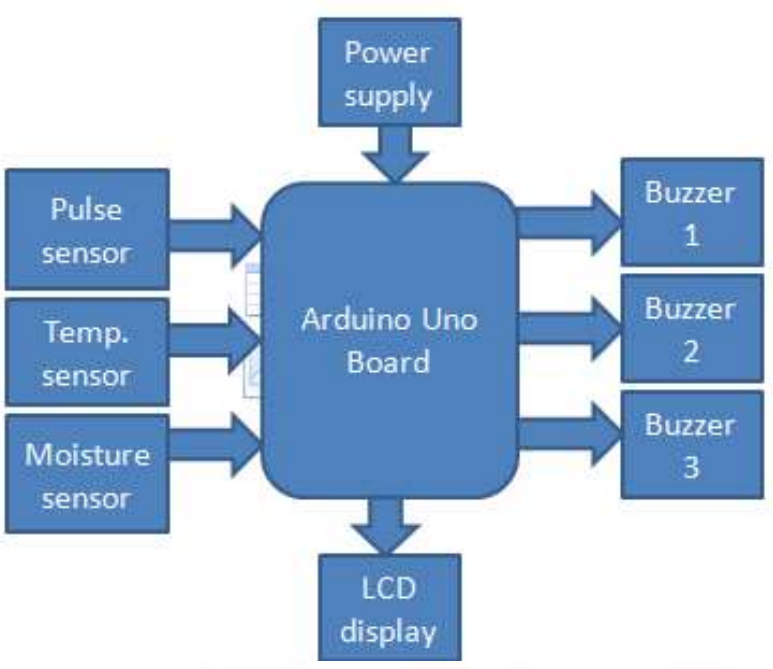

Fig (7) Block diagram

\section{Advantages:}

Monitors and detects the stress level. This system calculates stress level within fraction of seconds so that doctors can give best treatment to the patients immediately.

\section{Applications:}

This project is helpful in "PSYCHOLOGICAL DEPARTMENT and INSTITUTE”.

\section{FUTURE SCOPE:}

\section{METHODOLOGY}

In this project, pulse sensor is used to detect the heart beat rate of normal person. The moisture sensor senses the sweat of body and temperature sensor scenes the temperature of body. These three sensors are interfaced to the arduino board. When stress is increased, then these three parameters of body get affected. At output pin, buzzer is connected. When stress is increased, stress levels are indicated by three different buzzers. When level of stress is low, first sound buzzer is activated. When level of stress is medium, second sound buzzer is activated or else third buzzer is activated.

This system will be implemented by using IOT in future. Hence sensors, digital machines, objects or people that are provided with unique identifiers and transfer data over a network without requiring human to human or human to computer interaction.

\section{V. \\ RESULTS}

The pulse sensor, moisture sensor and temperature sensor catches level of stress and detects the level of stress that are sounded on three different buzzers connected across it as an alarm. Stress detector gives the levels of stress on that basis doctor gives treatment to the patient in hospital.

\section{CONCLUSION}

This system has been developed to find levels of stress. When stress reaches maximum, it is immediately informed to the respective doctor. The patient needs proper treatment to reduce stress. For reducing stress, doctors provide treatments such as a musical therapy or medicine. In musical therapy the level of stress can de decreased and the same can be 
monitored by using the stress level detector this will also monitored by this stress level system.

\section{REFERENCES}

1) colin D'souza ,Vijay Kumar U, Vinayak Baddi Vaibhav J Revankar-Design \& Implementation Of stress management system oct 2016

2) Joan De La cruz, GidleynDorlus Kara Hoehe, Erik Must, philippe Saintil-SMMURFS stress Management module using resistive force sensors.

3) Moisture sensor-www.researchdesignlab.com

4) PIEZO-PKM22EPPH4001-BO

5) ALTRONICdistrubution-specification sheet AlPhanumeric LCD modules. 